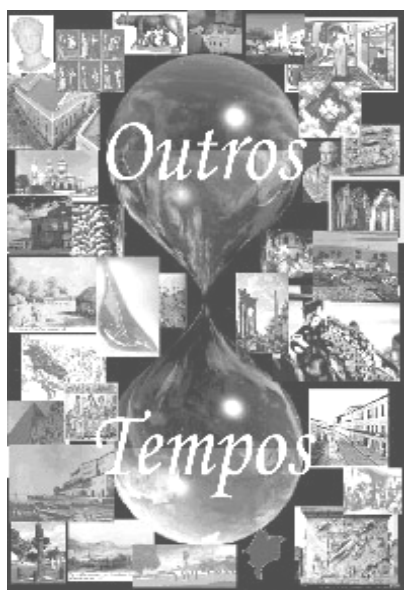

\title{
Surrealismo e Realismo Mágico em El Señor Presidente de Miguel Ángel Astúrias
}

\author{
Amina Maria Figueroa Vergara ${ }^{1}$ \\ Mestranda do Programa de Pós-Graduação FFLCH - USP, \\ sob orientação do Prof. Dr. Júlio César Pimentel
}

Resumo O presente trabalho tem por objetivo identificar elementos do surrealismo francês como vanguarda literária européia e do realismo mágico como um movimento de renovação da narrativa literária latino-americana, na obra El Señor Presidente de Miguel Ángel Asturias.

Palavras-chave: Guatemala, Miguel Ángel Asturias, Literatura hispano-americana, História e Literatura, Realismo Mágico.

\begin{abstract}
The present work aims to identify elements from the French surrealism, as an european literary vanguard movement, and from the magical realism as a renovation movement of the latin-american narrative literary, in Miguel Ángel Asturias' El Señor Presidente.
\end{abstract}

Keywords Guatemala, Miguel Ángel Asturias, Latin-american literature, History and Literature.

Recebido o título de Bacharel em Direito pela Universidad de San Carlos na Cidade da Guatemala no ano de 1923, Miguel Ángel Asturias fez o mesmo percurso que todo jovem latino-americano - com um mínimo de condições financeiras - realizava nos primeiros decênios do século XX: foi à Europa aprimorar seus estudos. Após ter escrito El problema social del índio como tese de graduação, Asturias aprofundou seus estudos em antropologia pela Sorbonne. Mesmo tendo o referido trabalho apontado para a questão agrária na Guatemala, assim como para a questão indígena, foi em Paris que Asturias conheceu a fundo a

\footnotetext{
${ }^{1}$ Este artigo insere-se nas pesquisas de mestrado que tem como projeto "A United Fruit Company e a Guatemala de Miguel Ángel Asturias", utilizando como fonte de pesquisa a trilogía bananera de Miguel Angel Asturias: Viento Fuerte, El Papa Verde, Los ojos de los Enterrados, e tendo como metodologia a relação entre Literatura e História para narrar a ação da United Fruit Company na Guatemala.
} 
complexa cosmologia dos povos autóctones de seu país. Foi à França para estudar os índios, a cultura originária de sua Guatemala, mas o que encontrou por lá, mudou radicalmente sua visão do homem e do mundo e influenciou, definitivamente, na criação de uma nova narrativa latino-americana. $^{2}$

Procurando pela palavra novo no dicionário, encontraremos as seguintes definições:

(...) que existe há pouco tempo, que tem pouco uso, nascente, incipiente, recém-chegado, outro, repetido, renovado, estranho, ignorado, visto pela primeira vez, original, ainda não devassado, não trilhado, cujo caráter mudou, feito pela primeira vez, acabado de fazer, em primeira mão, emendado, reformado, regenerado, inexperto, inexperiente ${ }^{3}$.

No período entre-guerras, mais precisamente durante a década de 1920, a partir da consternada constatação da decadência e colapso dos valores e instituições da civilização liberal, era tudo isso que as vanguardas artísticas européias procuravam. Todos buscavam ávida e vorazmente este tal novo. O novo homem, o novo pensamento, a nova estética, a nova moral, a nova política, a nova ordem.

Os escritores de vanguarda combatiam pela novidade. Ser novo era então, mais importante que ser profundo, sincero ou brilhante. Sendo novo, conseguia-se alcançar um novo patamar e talvez criar uma escola ou revista, mesmo que durasse um curto período. As vanguardas de entre-guerras eram fugazes, combativas, juvenis, audazes, atrativas.

Tudo o que se apresenta como "novo", entretanto, nunca rompe de maneira definitiva com o "antigo". É o que nos aponta Angela de Castro Gomes ao mostrar que a força da tradição está em sua constante transformação e atualização: "(...) a noção de tradição não pode nem deve ser tomada como o 'passado' ou o 'atraso', isto é, como um obstáculo à mudança, seja ela de que natureza for" (GOMES, 1999, p.26). Sendo assim, o novo, reivindicado pelas vanguardas literárias teria dois sentidos: como algo que nunca se viu, inédito, original e como algo que já existiu, mas que foi remendado, reformado, regenerado, ou seja, com o perdão da redundância, que se encontra "novamente novo", renovado.

\footnotetext{
${ }^{2}$ A partir desse estudo aprofundado dos índios e seus mitos da Guatemala, Asturias escreveu Leyendas de Guatemala, publicada em 1930. A língua guatemalteca regional, a abundância de termos indígenas e metáforas literárias desta obra de Asturias, podem espantar o leitor em um primeiro momento. Entretanto, as imagens coloridas, a melodia, aos elementos da natureza nos envolvem e nos convidam a conhecer coisas de outro mundo que poderiam muito bem ser deste.

${ }^{3}$ Dicionário Michaelis, Editora Melhoramentos, 2002. Creio que o uso do dicionário se faz importante para retomarmos o real significado das palavras, que em muitos casos, vai se perdendo ao longo do tempo.
} 
Mesmo que a tradição ainda esteja presente, o aspecto mais latente das vanguardas está em seu "sentido radical", que se dá ao propiciar reflexões que alcançam a raiz mesma dos problemas culturais e/ou sociais. Elas não são só importantes porque tenham renovado as formas de fazer arte, mas também por terem provocado desafios ao conceito mesmo de forma artística. Portanto, as vanguardas são movimentos que põem tensão na própria arte e, tencionando seu arco, promovem uma reflexão sobre sua própria atividade (POZUELO, p. $42)$.

Quando Asturias aportou em Paris, na década de 1920, as vanguardas artísticas se encontravam em frenética efervescência. E foi o último dos "ismos" franceses, o Surrealismo de André Breton e outros, que influenciaria, daquele ponto em diante, toda a sua obra.

Outro aspecto das vanguardas, além da incessante busca pelo novo, será a liberdade estética. Liberdade no sentido mesmo de "independência, autonomia e ousadia, de poder exercer livremente a sua vontade" ${ }^{4}$. Liberdade esta, que será exacerbada pelo Surrealismo. Sendo o mais engajado, digamos assim, dos movimentos vanguardistas, o Surrealismo francês tinha como principal proposta a liberação, tanto individual quanto social. Foi o único movimento entre as vanguardas, de acordo com Jorge Schwartz, "que chegou a propor uma atuação de ordem política em prol de uma revolução social como meio de liberar o indivíduo de todos os seus condicionamentos" (SCHWARTZ, 1995, p. 388), tendo, a conquista de um grau mais alto de consciência crítica, como principal objetivo.

O Surrealismo celebrava a sociedade industrial, magnificava os aspectos da modernidade e os dilatava até assumi-los como "novos mitos". A máquina era celebrada e a arte podia abraçar o progresso como parte de si mesma. Destacou-se, no Surrealismo, seu otimismo em intervir artisticamente - desde a teoria à realização formal - na vida prática. Inseria-se dentro de uma nova humanidade, onde a estética adquiria ambição revolucionária. Reabilitando o indivíduo, como queria Breton, reabilitava-se o ser coletivo e se compreendia a natureza, através do ser humano (SCHWARTZ, 1995, p.390).

\footnotetext{
${ }^{4}$ Dicionário Michaelis.
} 
Ao lado deste aspecto da liberdade estética, a escrita surrealista, por exemplo, volta-se para os meandros de uma realidade inter e intra-subjetiva, adotando procedimentos de alto poder analítico - como o monólogo interior e o jogo de focos narrativos ${ }^{5}$ - deslocando assim, as fronteiras do realismo psicológico para os territórios do sonho e do delírio. Não é exagerado afirmar então, que a única via que conduz o novo humanismo reivindicado pelo surrealismo, seria a que mistura e identifica em si mesma, poesia (sonho) e vida (homem). Tal mistura ultrapassa os limites da literatura e da arte em direção a uma meta delirante, onde sonho e ação se fundem, nos impondo uma conduta que implica a liberação total do espírito e nos comprometendo com a imprescindível e implacável missão de transformar o mundo e mudar a vida. (MARTIN, C., 1986, p.13).

Entretanto, afirmar que Asturias simplesmente absorveu todo esse turbilhão de novidades e liberdade e que a partir dele escreveu sua obra mais profunda e visceral — além da mais lida, analisada e comentada (MARTIN, G.,1999) - El Señor Presidente, seria um equívoco.

Em sua temporada na Paris vanguardista, que durou cerca de dez anos (de 1924 a 1933), Asturias manteve assíduo contato com diversos escritores latino-americanos, que também se encontravam em um exílio voluntário, tais como Jorge Luís Borges, Arturo Uslar Pietri, Augusto Roa Bastos, Alejo Carpentier, Pablo Neruda e César Vallejo:

Los escritores latino-americanos descubren la llamada de lo nuevo en sus respectivos países, pero como sucedió con el modernismo necesitan estar fisicamente en Europa, para tal vez huir de las tiranias de las estéticas conocidas (MARCO,1987, p.18).

Faz-se importante ressaltar, que todos esses escritores foram precedidos pelo poeta nicaragüense Rubén Dario, iniciador, segundo alguns críticos, do modernismo literário em língua hispanoamericana com seu livro $A z u l . .$. , de 1888, que recolhe tanto relatos em prosa, como poemas e cuja variedade métrica chamou a atenção da crítica (MARCO,1987, p.19) ${ }^{6}$.

\footnotetext{
${ }^{5}$ BOSI, Alfredo. "Parábola das vanguardas Latino-americanas", in, SCHWARTZ, 1995, p. 27

${ }^{6}$ Azul..., já apresenta algumas preocupações características de Darío, como a insatisfação ante a sociedade burguesa em o relato de "El rey burguês", por exemplo. Em 1890 é publicada a segunda edição do livro, com
} 
Em efeito, Darío, assim como os demais escritores modernistas latino-americanos, já em fins do século XIX, rechaçava os modelos literários espanhóis, em voga, em especial a poesia de la Restauración, preferindo o parnasianismo francês. A partir de uma atitude de independência frente à herança espanhola, Darío catapultou sua obra latino-americana a partir da Europa, entretanto, se aproximando mais do ideal parisiense do que do madrilenho.

À parte de Neruda e Vallejo, que residiam na Espanha - o primeiro por seu alto grau de ligação com Federico García Lorca, chegando mesmo a combater na Guerra Civil Espanhola e o segundo porque considerava a Espanha e não a França, a "mãe-pátria de toda a América Latina" (MARCO, 1987, p. 30) - todos os demais escritores, entre eles Asturias, tinham Paris como seu ponto de encontro, ou ainda, seu espaço público, lugar onde elaboravam suas obras a partir de matizes socioculturais daqueles países, que, de bom ou mal grado haviam, por hora, abandonado. Sendo assim, El Señor Presidente poderia ser considerada uma novela sobre a Guatemala, desde Paris ${ }^{7}$.

O grande pioneirismo de Asturias foi unir as profundas explorações dos domínios do subconsciente proclamadas pelo Surrealismo e as manifestações socioculturais autóctonas da Guatemala. Não se trata, porém, de uma simples soma entre o Surrealismo e as lendas maias, mas antes de um movimento circular (MARTIN, C., 1986, p. 226).

Asturias parte das tradições dos povos originários, passando pelos domínios do Surrealismo, para então regressar, com uma nova visão do mundo e do homem, aos seus mitos e lendas guatemaltecos. Aqui, verificamos a formação do realismo mágico ${ }^{8}$. É importante insistir que este pioneirismo não está no caráter surrealista de suas obras - que também verificamos em livros de Jorge Luís Borges, Julio Cortázar, Arturo Uslar Pietri, Augusto Roa Bastos - mas sim, no impulso recebido através do contato fecundo com o Surrealismo e na aproximação de dois mundos, Europa e América, que incide, fundamentalmente, em uma nova cosmovisão que se apresentará em Leyendas de Guatemala (1930), El Senõr Presidente (1946), Hombres de Maíz (1949), e na Trilogía Bananera: Viento Fuerte (1949), El Papa

novos textos, entre os quais uma série de sonetos. Outras obras importantes de Darío são, Prosas profanas y otros poemas (1896) e Cantos de vida y esperanza (1905), (MARCO,1987).

${ }^{7}$ A novela surgiu a partir de um conto de Asturias, originalmente chamado de Tohil (uma divindade da mitologia maia-quiché) e de longas conversas com Uslar Pietri. Asturias chegou a reescrevê-la diversas vezes (MARCO, 1987, p.32).

${ }^{8}$ Ou o real maravilloso americano de Alejo Carpentier, ou ainda, o realismo fantástico de Arturo Uslar Pietri e Gabriel García Márquez. (MARTIN, C. 1986, p.224) 
Verde (1954), Los ojos de los Enterrados (1960). O realismo mágico de Asturias seria menos antirrealista (em oposição ao realismo literário anterior) e mais uma ampliação do conceito de realidade, um novo modo de representá-la, superando o Realismo e o Naturalismo. Ele implica o descobrimento de mundos livres da causalidade consciente, com associações e intuições que superam a ordem, assim como a representação realista e conceitual do mundo, sem, por isso, considerar a fantasia como algo incoerente.

Asturias percebe que todas as lendas de sua terra, inclusive as mais ininteligíveis, possuíam sua base em um acontecimento real, ou seja, os relatos fantásticos provêm da mais profunda e constatável realidade. Na antiga sociedade maia (como na maioria das sociedades ancestrais), as lendas e mitos aparecem como um meio de dar sentido a algo de difícil compreensão, como por exemplo, os fenômenos naturais.

Por se tratar de uma novela, ao mesmo tempo, política e vanguardista (MARCO, 1987, p.68), El Señor Presidente pode ser inserida em um pequeno grupo de "novelas de ditadura"9.

O político está no humor negro trazido do barroco espanhol, transformado em um ultrabarroco onde, sem "dar nome aos bois", Asturias discorre, de maneira até grotesca, sobre a ditadura de Manuel Estrada-Cabrera ${ }^{10}$. Grotesca, mas não irreal, pois a relação entre a experiência vivida pelo povo guatemalteco e a novela de Asturias, resulta estreita. O novelista pode até deformar, exagerar e modificar a realidade, mas, as situações e personagens que podem parecer inverossímeis, refletem seres e ações reais. Algumas cenas de maior truculência, como os assassinatos e as torturas, não são imaginárias. Asturias nos mostra que a imaginação dificilmente supera a realidade, por mais estranha que esta pareça. Ou seja, o autor não faz, senão imaginar um número definido de possibilidades, aproximadamente as mesmas que configuram a complexidade da vida humana.

\footnotetext{
${ }^{9}$ Seriam outras "novelas de ditadores": Tirano Banderas, de Valle-Inclán, Yo, el Supremo, de Augusto Roa Bastos e El Otoño del Patriarca, de García Márquez. (MARCO, 1987, p. 67).

${ }_{10}$ Presidente da Guatemala, de 1898 a 1920, comandou uma das ditaduras mais corruptas e arbitrárias da América Central. Incentivou a construção de estradas, ferrovias e portos. A United Fruit Company converteu-se na principal força econômica da Guatemala durante seu mandato.
} 
O vanguardismo está em El Senõr Presidente, por esta obra ter sido uma das primeiras novelas latino-americanas a propor uma relevante mudança na linguagem literária, ao explorar a relação entre mito e linguagem e entre ambos e os desejos inconscientes, e ao encontrar a maneira de transformar o aspecto formal do texto literário dentro de uma concepção profundamente política e comprometida com a escritura.

Entretanto, El Senõr Presidente não pode ser considerada como um mero retrato de um sistema ditatorial, pois possui uma identidade artística autônoma. É um mundo literário inspirado pela corrupção, pelos abusos da autoridade política e pelo terror que caracterizaram alguns regimes latino-americanos, e que ainda hoje persistem em algumas sociedades. A novela se inspira em algumas lembranças de adolescência, de Asturias, que, quando estudante, participou diretamente de movimentos pacíficos contra a ditadura de Estrada Cabrera. (SÁNCHEZ, 1968, p.430).

El Senõr Presidente possui uma dedicada vocação experimental e artística, ou seja, busca configurar uma autonomia expressiva, mediante a linguagem, ao mesmo tempo em que descreve a corrupção do corpo social, descobrindo os fios condutores que comunicam o poder político e as classes despossuídas.

O enredo da novela desenvolve-se a partir do assassinato do Coronel Parrales Sonriente, muito considerado pelo "Presidente da República, ditador supremo do país" (El Señor Presidente, con la tierra que le andaba bajo los pies y la casa sobre el sombrero $)^{11}$. Em reação à perda de um companheiro de tão alta estima do benemérito da pátria, desencadeia-se uma onda de violência sem precedentes. A cena do assassinato se dá no Portal del Señor, ponto perto da Praça de Armas, onde os mendigos e pedintes se amontoavam durante a noite.

Entre meio dormido e meio acordado, entre pesadelo e realidade, um dos mendigos, o deficiente mental Pelele, em um rompante de fúria - pois não podia dormir por conta de um outro, que não cessava em chamar por sua mãe (madre...!!!!) - atacou e assassinou o Coronel Parrales que, em uma cruel brincadeira, remendava o tal mendigo inquieto. Pelele consegue fugir, mas seus companheiros são levados a interrogatório (leia-se, sessões de tortura). Um dos

\footnotetext{
${ }^{11}$ Todas as passagens da novela foram retiradas da edição El Señor Presidente, Unidad Editorial, Madrid, 1999.
} 
mendigos, el Mosco, cego e inválido, é torturado até à morte por não afirmar que o assassino do Coronel Parrales seria o General Canales, então desafeto do Auditor General de Guerra, o qual conduzia a sessão de tortura.

Para livrar o General Canales da "intriga" feita pelo Auditor, o benemérito da pátria, envia seu braço-direito e "faz-tudo", Miguel Cara de Ángel (el favorito, bello y malo como satán), à casa do General Canales para aconselhá-lo a fugir, mas na verdade seria tudo um plano para se livrar de Canales - que apresentava queixas quanto às práticas, no mínimo obscuras, da polícia secreta, tão cara ao benemérito da pátria - e o assassinato do Coronel Parrales Sonriente, vinha a calhar.

Entretanto, Cara de Ángel não contava em cruzar com Camila (pelo en llamas negras alborotado, náufragos los ojos verdes), filha de Canales. Camila - que, com a fuga do pai, passará a acompanhar Cara de Ángel quando seus tios a rejeitam por medo de represálias da polícia secreta - ao fim da novela será a redenção e condenação de Cara de Ángel. Cedendo ao amor de Camila, Cara de Ángel trairá a confiança do benemérito da pátria, sofrendo na pele as mesmas torturas que tantas vezes havia executado.

A novela não se desenrola de forma linear; ela apresenta uma temporalidade circular, que se inicia e termina no Portal del Señor, que por fim é destruído por el Señor Presidente, como meio de dispersar aqueles miseráveis, já zoomorfizados:

La noche los reunia al mismo tiempo que a las estrellas. Se juntaban a dormir en el Portal del Señor sin más lazo común que la miseria, maldiciendo unos de otros, insultandose a regañadientes con tirria de enemigos que se buscan pleito, riñendo muchas veces a codazos y algunas con tierra y todo, revolcones en los que, tras escupirse, rabiosos, se mordían (p.11).

A oposição entre luz e sombra, real e imaginário, perpassa toda essa miséria coletiva, onde, as coronhadas da polícia de sentinela na madrugada eram como vultos, "fantasmas envueltos en ponchos", a um dos quais, no caso o Coronel Parrales, Pelele não hesitou e "le enterró los dedos en los ojos, le hizo pedazos la nariz a dentelladas y le golpeó las partes con las rodillas hasta dejarlo inerte" (p.15). Pelele foge e se esconde no lixo como um animal: "La noche entera estuvo quejándose quedito y recio, quedito y recio como perro herido... Erre, erre, ere... Erre, erre, ere... Erre-e-erre-erre-e-erre..." (p.21). Sem tomar consciência do que acabara de fazer, conseguiu - finalmente - dormir como um animalzinho. 
Situações de tortura, como a do cego inválido - que mesmo entregando Pelele não é poupado - estão presentes ao logo de toda a novela. Asturias nos mostra seqüências de violência gratuita do homem contra o homem, justificadas em determinado momento, pelo ditador onipresente, como forma de manutenção da ordem e da moral nacionais. Qualquer semelhança, não é mera coincidência ${ }^{12}$.

A sessão de tortura de Niña Fedina, - amiga de Camila e que se encontrava por acaso na casa do General Canales na noite de sua fuga - que ouvindo seu filho (de quem Camila seria madrinha) chorar de fome, era impedida de amamentá-lo, não passa sobremaneira, desapercebida pelo leitor:

Ella se lanzó por una puerta, pero le salieron al paso trés hombres, trés bestias negras que sin trabajo quebraron sus pobres fuerzas de mujer. En aquél forcejeo inútil se le soltó el cabello, se le salió la blusa de la faja y se les desprendieron las enaguas. Pero qué le importaba que los trapos se le cayeran. Casi desnuda volvió arrastrándose de rodillas a implorar del Auditor que le dejara dar el pecho a su mamoncito."(p.104) "Uno de los hombres que cubrían la puerta la arrojó al suelo de un empujón; otro le dió un puntapié que la dejó por tierra. El llanto y la indignación le borraban los ladrillos, los objetos: No sentia más que el llanto de su hijo (p.105).

Asturias nos apresenta a ditadura quase como um panóptico foucaultiano, a partir do qual o ditador compara-se ao temível Tohil, divindade maia, cujos seus tentáculos estariam na polícia secreta. É como se o país vivesse preso em um constante sonho, sem conseguir discernir o que é realidade e o que é imaginação. Impedir uma mãe desesperada de amamentar seu filho que chora (Su hijo había dejado de existir... con ese modo de moverse, un poco de fantoche, de los que en el caos de su vida desecha se van desatando de la cordura, Niña Fedina alzó el cadáver que pesaba como una cáscara seca hasta juntárselo a la cara fibrosa, p.131) ou tripudiar sobre o cadáver de um cego (Viejo embustero, de nada habría servido su declaración, porque era ciego!), não poderiam ser ações humanamente reais, eram, pois, surrealmente inumanas.

\footnotetext{
12 "(...) el proceso de modernización que, explicitamente o no, tenía por objeto separar a los militares de la política, significó el fin de la hegemonía de los civiles en casi todos los países de la región. Las medidas defensivas destinadas a estabilizar la vida política y reglamentar el funcionamento armonioso del Estado provocaron, por el contrario, quebrantos institucionales que condujeron a la ususrpación militarista. Al emanciparse de la sociedade civil y la clase dirigente, las fuerzas armadas se repolitizan sobre nuevas bases, de acuerdo a su própria lógica organizativa.", ROUQUIÉ, Alain. "El Estado Militar en América Latina", Teoria y Práctica, México: Siglo XXI, 1990, p. 86.
} 
Para manter a ordem, tal qual queria o Presidente da República, a polícia secreta valiase da alta fidelidade da população para com seu comandante supremo. Eram inúmeros os pedidos, informes, mas, principalmente, as delações que podiam, mesmo, levar a bárbaras humilhações, prisões arbitrárias, torturas e assassinatos. Ainda assim, a "segurança do Estado" e a "preservação" da vida do Señor Presidente, eram incontestes:

Alejandra (...), manifiesta que por quedar su establecimiento comercial pared de por medio de la Fonda El Tus-Tep, ha podido observar que en esta última se reúnen frecuentemente, y sobre todo por las noches, algunas personas con el cristiano propósito de visitar a una enferma [no caso Camila, que adoecera após não ser recebida na casa de seus tios]. Que lo pone en conocimiento del Señor Presidente porque ella se le figura que en esa fonda está escondido el general Eusébio Canales, por las conversaciones que ha escuchado a través del muro, y que las personas que allí llegan conspiran contra la seguridad del Estado y contra la preciosa vida del Señor Presidente (p.137).

Entretanto, o ditador supremo não poderia contar somente com essa "rede de delações" e com a consentida arbitrariedade de sua polícia secreta. É neste momento que o sentido da ditadura se dá, desde a ótica do poder. É quando o Presidente da República confessa a Cara de Ángel os motivos que o levam a fazer uso do poder, sob a forma personificada, pois, a raiz de seu poder ditatorial, está na displicência dos próprios cidadãos, incapazes de organizar por si próprios a vida pública, ou seja, ele estaria cercado de "gente de voy":

(...) gente que tiene la mejor intención del mundo para hacer y deshacer, pero que por falta de voluntad no hace ni deshace nada, que ni huele ni hiede, como caca de loro. Y es así como entre nosostros el industrial se pasa la vida repite y repite: voy a introducir una fábrica, voy a montar una maquinaria nueva, voy a esto, voy a lo outro (...), al señor agricultor, voy a implantar un cultivo, voy a exportar mis productos; el literato, voy a componer un libro, el profesor, voy a fundar una escuela; el comerciante, voy a intentar un negocio, y los periodistas... (p.229).

Luz e sombra voltam a figurar no enredo, entretanto, agora, não mais na miséria da cidade, mas na fuga do General Canales pela selva. Situação em que Canales se encontrava por ter discordado dos métodos escusos da polícia secreta. De militar orgulhoso de seu "capis", a revolucionário insurgente, junto aos índios, Canales acaba por ser cooptado pelos tentáculos do panóptico e morre envenenado. Mas, antes disso, terá contato com outro tipo de miséria, a miséria do indígena. ${ }^{13}$

\footnotetext{
${ }^{13} \mathrm{Na}$ edição de 50 anos de sua tese "El problema social del índio", em 1971, Asturias faz uma advertência: "La situación del indígena guatemalteco no ha mejorado desde entonces, en lo fundamental, bien que el progreso le haya hecho partípice de algunos de sus benefícios. La inercia del progreso. El gran problema de la tierra que le
} 
O general também já não identifica a diferença entre o real e o imaginário, após ter ouvido a história de um indígena que, por não ter acatado à ordem do governo de plantar determinada fruta em sua finca, foi preso, apanhou e parou no hospital, teve seus filhos pequenos presos e, ao se recuperar, sua terra havia sido vendida a "un señor extranjero" por uma quantia ínfima:

En el corazón del viejo Canales se desencadenaban los sentimientos que acompañan las tempestades del alma del hombre de bien en presencia de la injusticia. Le dolía su país como si se le hubiera podrido la sangre. Le dolía afuera y en la medula, en la raiz del pelo, bajo las uñas, entre los dientes. Cuál era la realidad? No haber pensado nunca con su cabeza, haber pensado siempre con el quepis. Ser militar para mantener en el mando a una casta de ladrones, explotadores y vendepatrias endiosados es mucho más triste, por infame, que morirse de hambre en el ostracismo. A santo de qué nos exigen a los militares lealtad a régimenes desleales con el ideal, con la tierra y con la raza... (p.166).

Ainda assim, para el Señor Presidente, a traição de Canales (No me refierio a Canales ni a sus secuases: la muerte me a sido y será mi mejor aliada, Miguel!) não era nada, se comparada à traição de Cara de Ángel. Após muito relutar ao amor pela filha de um "traidor da pátria", Cara de Ángel irá ceder ao ver Camila ser rejeitada por sua família - e pensando que seu pai havia realmente traído seu comandante supremo - e adoecer gravemente. Somente um matrimônio in extremis, no leito moribundo, irá salvá-la.

Mesmo após sua redenção, através do amor, sua lealdade para com o Presidente da República, não se havia abalado. Ainda com Camila adoecida, Cara de Ángel vai ao encontro de El Señor Presidente. Após uma conversa um tanto quanto insólita, com um presidente um tanto quanto alterado (Al asomar a la puerta vió un bosque de botellas en una mesa redonda y un plato de fiambre, guacamole y chile pimiento), ambos entram em acordo: Cara de Ángel iria a Washington resolver assuntos de "suma importancia". Mas, ainda no trem para a costa, Cara de Ángel é atocaiado e preso. E, após tantos anos de servidão, experimenta o inferno (como na descrição mesma de Dante, onde se deve deixar do lado de fora toda a esperança) por ter traído o deus Tohil:

Dos horas de luz, veitidós horas de oscuridad completa, una lata de caldo y una de excrementos, sed en verano, en invierno el dilúvio; ésta es la vida en aquellas carcéls subterráneas (p.248).

debe ser devuelta sigue planteado. Este és el problema numero uno. Urge una reforma agrária completa y la creacion de cooperativas de producción, venta y consumo. Nada se ha hecho hasta ahora de efectivo frente el segundo gran problema: el analfabetismo. Todo sigue igual. Ni siquiera hay directivas suficientemente estudiadas, sobre si conviene enseñar a leer y escribir al índio, en sus lenguas nativas, o en español." In, www.literaturaguatemalteca.org. 
Camila, ainda doente, mas sem saber que estava grávida, quase morre de melancolia, sem notícias do marido. Desespera-se, ao ser propositalmente mal informada de que Cara de Ángel já estaria em Washington, há muitos meses, e, ao lhe ter sido negada uma audiência com o Presidente da República, assim como um passaporte para sair do país. Vai para o campo, onde tem seu filho e de onde não sairá nunca mais.

Miguel Ángel Asturias inovou, ao mostrar uma grande destreza lingüística em $E l$ Señor Presidente. Tratam-se de novos matizes de uma linguagem poética cheia de imagens e de novos termos. Sua estrutura é nova e suas técnicas ousadas. As ruas da cidade aparecem descritas de formas diversas, mas sempre com a "miséria compartilhada" do Portal del Señor. E mesmo com toda a dor de seus habitantes, há a esperança (o amor de Cara de Ángel e Camila, seu filho juntos) na certeza de que a crueldade e o horror são efeitos de uma sociedade humana disforme.

Mostrando uma enorme sensibilidade ante o homem e, sobretudo ante o indígena guatemalteco $^{14}$, Asturias logrou superar a literatura meramente de compromisso, formando um corpus que enuncia a problemática social da Guatemala, sem cair no panfletário. Desde de sua tese universitária, sempre buscou revelar ao mundo a identidade guatemalteca e identificar-se totalmente com ela:

As paisagens familiares recebem nas lendas de Asturias uma aura mágica de lugares estranhos vistos como se fora pela primeira vez. Eis um caso em que o contato com o surrealismo despertou no poetanarrador o desejo de penetrar no que há de potencialmente misterioso na mais trivial das relações entre homem e homem, homem e mulher, homem e natureza (BOSI, p.26).

Ao fazer a junção entre técnicas européias e elementos tanto estilísticos como temáticos, de uma tradição guatemalteca autóctone, Asturias reconstrói e recria mitos para,

\footnotetext{
14 "Al final de la novela, como habían hecho los narradores indigenistas, el autor incluye un vocabulario. Porque la introducción de términos de origen indígena podía, en el momento de la publicación, hacer retroceder a algún pusilámine lector. Serían los narradores de la generación posterior a Asturias [García Márquez, Vargas Llosa] los que darían como natural un castellano enrraizado en el sustrato indígena." (MARCO, p.80)
} 
talvez, tentar explicar o inexplicável: quando a realidade supera a ficção e se torna tão incoerente que pode passar com facilidade à categoria de inverdade.

De acordo com Luis Alberto Sánchez, "El odio en Asturias no inculpa o destruye; al contrario, construye un mundo de ridículo frente al objeto de su diatriba y otro mundo de superación de parte de quienes él ama y exalta." (SANCHÉZ, 1968, p.492)

Sendo assim, Asturias deforma a realidade, até transformá-la em caricatura. Deforma a exploração do homem pelo homem, deforma a miséria, o autoritarismo e a arbitrariedade, os despossuídos, os fenômenos da natureza, as paisagens e a terra. Ou seja, desconstrói, reconstrói, transforma e mesmo transcende o homem, de forma violenta e por vezes injuriosa. Vale-se do elemento fantástico para talvez, tentar explicar ações humanas que nos parecem tão irreais que, somente através de outros matizes teóricos, que não os tradicionais, podem ser mastigados, digeridos e compreendidos. Aqui, o uso da literatura e mais especificamente, do gênero literário Realismo Mágico, é uma maneira de o historiador atenuar suas inquietações quanto ao método de análise dos fatos históricos, deslocando-se para outras áreas do conhecimento.

\section{Fonte.}

ÁNGEL ASTURIAS, Miguel. El Señor Presidente, Unidad Editorial, Madrid, 1999.

\section{Bibliografia.}

ACHUGAR, Hugo e VERANI, Hugo. Narrativa vanguardista hispanoamericana, Coordinación de Difusión Cultural, Dirección de Literatura, UNAM. Ediciones del Equilibrista, México, 1996.

BELluZZO, Ana Maria de Moraes (org.). Modernidade: vanguardas artísticas na América Latina, São Paulo, Memorial, Unesp, 1990.

LIMA, Luiz Costa. História, Ficção, Literatura, Companhia das Letras, São Paulo, 2006.

FACINA, Adriana. Literatura e Sociedade, Coleção Passo-a-Passo no 48, Jorge Zahar Editor, Rio de Janeiro, 2004.

LIMA, Luiz Costa. História, Ficção, Literatura, Companhia das Letras, São Paulo, 2006. 
MARCO, Joaquín. Literatura hispanoamericana: del Modernismo a nuestros días, Colección Austral, Editora Espasa Calpe, Madrid, 1987.

MARIA POZUELO YVANCOS, José. Ventanas de la ficción. Narrativa hispánica, siglos XX y XXI, Ediciones Península, Barcelona, 2004.

MARTIN, Carlos. Hispanoamerica: Mito y Surrealismo, Nueva Biblioteca Colombiana de Cultura, Bogotá, 1986.

MARTIN, Gerald. Estudios Introductórios para las Obras completas de Miguel Ángel Asturias (para El Señor Presidente), editadas pela Colección Archivos, 1999. Disponible em www.literaturaguatemalteca.org.

SÁNCHEZ, Luis Alberto. Proceso y Contenido de la Novela Hispano-Americana, $2^{\mathrm{a}}$ Edición, Biblioteca Románica Hispânica, Editorial Gredos, Madrid, 1968.

SCHWARTZ, Jorge. Vanguardas Latino-americanas - Polêmicas, Manifestos e Textos Críticos, São paulo, Edusp, Iluminuras, FAPESP, 1995. 